\title{
La arquitectura como objeto cultural
}

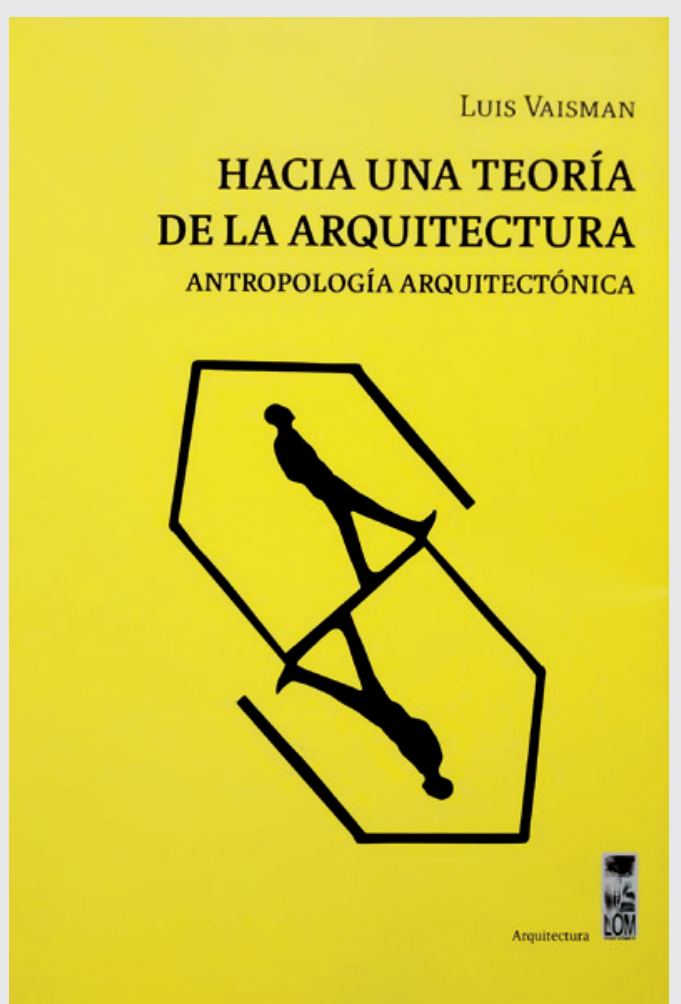

"HACIA UNA TEORÍA DE LA ARQUITECTURA. Antropología Arquitectónica"

Luis Vaisman · LOM Ediciones · 2015 · Santiago, Chile
La década de los 60, en el pasado siglo XX, fue prolífica en publicaciones de ensayos sobre temas vinculados a la arquitectura, textos como LA POÉTICA DEL ESPACIO de Gastón Bachelart, INTENTIONS IN ARCHITECTURE de C. Norberg-Schulz o ARQUITECTÓNICA de J. R. Morales, por nombrar solo algunos, removieron las bases ideológicas de la arquitectura en varios sentidos aún no superados. La tesis de Luis Vaisman, discípulo de J. R. Morales, es una especie de corolario de esa década cuestionadora y viene a profundizar y continuar el camino trazado por el dramaturgo, ensayista y profesor españolchileno, en sus conocidos textos ARQUITECTÓNICA I y ARQUITECTÓNICA II.

Influenciado fundamentalmente por las ideas de Heidegger sobre la ineludible condición humana del habitar, la fenomenología de la percepción de Merleau-Ponty y la teoría del espacio existencial de Norberg-Schulz, Vaisman transita por los caminos de la antropología filosófica formulando preguntas medulares para intentar llegar a lo que llama el origen de la arquitectura, no el origen primigenio en los albores de la humanidad, sino en el sentido heideggeriano de aquello que le permite ser de un cierto modo, es decir, la gestación, consistencia y sentido del espacio donde el hombre vive, hasta convertirlo en arquitectura Preguntas similares a las formuladas por Jean Paul Sartre a fines de los 40 en su ensayo Qu'EST-CE QUE LA LITÉRATTURE?: ¿̇qué es escribir?, ¿̇por qué escribir?, ¿̇para quién se escribe?, preguntas que Vaisman, en su temprano acercamiento a la literatura debe haber incorporado en su devenir arquitecto-literato.
La pregunta żqué es la arquitectura? se constituye en la estructura y el sentido de la disquisición teórica. Debido a la imprecisión del término y a los distintos significados que se le atribuyen, la pregunta sigue siendo válida y probablemente sea necesario repetirla más de una vez, según desde dónde se formule.

Hacer, pensar y usar, los modos mediante los cuales el hombre se relaciona con la arquitectura, son las hebras que el autor utiliza para llegar a la teoría de la arquitectura y delimitar su campo. Modos que pocos se atreverían a cuestionar, pero que hoy percibimos inconexos, con un hacer que no da tiempo ni valor al pensar, con un pensar que no logra traspasar las obras concretas y con una gran masa de usuarios que deben contentarse con vivir en una construcción en reemplazo de una obra de arquitectura.

El libro incluye otro interesante aporte en las más de 250 notas aclaratorias y referencias bibliográficas, que no solo nos remiten a las fuentes del autor en la filosofía, antropología, arquitectura, fenomenología, estética, literatura, lingüística, entre otros saberes, sino que constituyen un cuerpo paralelo que nos abre variadas puertas para profundizar en determinados temas o autores.

Aunque los artículos de Luis Vaisman circularon siempre en medios académicos, esta publicación de LOM viene a hacer justicia al autor, injustamente acallado, como muchos, durante la intervención de la Universidad de Chile impuesta por la dictadura militar. Poco importarán los 40 años de espera si esta publicación sirve para reabrir el debate profundo sobre la arquitectura, más allá de las modas y los "nichos" actuales y para reposicionar la teoría de la arquitectura en la formación de los arquitectos. 